\title{
Factors associated with changes in creatine phosphokinase (CPK) in trauma patients submitted to the "Red Wave", with evolution to rhabdomyolysis
}

\section{Fatores associados à variação da creatina fosfoquinase (CPK) em pacientes vítimas de trauma, submetidos à "Onda Vermelha", com evolução à rabdomiólise}

\author{
Mario Pastore Neto'; Rafael Valério Gonçalves33; Carla Jorge Machado²; Vivian Resende, TCBC-MG1
}

\begin{abstract}
A B S T R A C T
Objective: to identify and analyze factors associated with plasma creatine phosphokinase (CPK) levels in trauma victims with progression to rhabdomyolysis. Methods: we conducted a prospective, longitudinal study, with 50 patients submitted to the "Red Wave" protocol, with evolution to rhabdomyolysis after hospital admission. We studied the variables age, gender, trauma scores, mechanism and outcome, CPK at admission and final, intervals of days between laboratory evaluations, surgery and complications. We stratified CPK values in $<500 \mathrm{~L} / \mathrm{L}$, $\geq 500$ - $<1000 \mathrm{U} / \mathrm{L}$, and $\geq 1000 \mathrm{U} / \mathrm{L}$, with calculation of the difference between the initial and final values. Results: at admission, $83 \%$ of patients ( $n=39$ ) had CPK $\geq 1000 \mathrm{U} / \mathrm{L}$, with predominance of blunt trauma and thoracic injury $(p<0.05)$, as well as orthopedic fracture, acute renal failure and gastrointestinal bleeding, CPK being lower in those without acute renal injury, with a trend towards statistical significance. There were no differences in final CPK stratification. Factors that were independently associated with the greater CPK variation were, positively, hospitalization time greater than one week and compartment syndrome, and negatively, acute renal injury. Conclusion: the CPK level of 1000U/L remains the lower limit, with importance for early intervention in worsening conditions such as digestive hemorrhage, acute renal injury and compartment syndrome, which implied greater absolute differences between initial and final CPK, in addition to blunt trauma, thoracic injury and orthopedic fracture.
\end{abstract}

Keywords: Rhabdomyolysis. Creatine Kinase. Emergency Medical Services.

\section{INTRODUCTION}

$\mathrm{R}$ habdomyolysis is a syndrome with a high life threatening potential, characterized by skeletal striated muscle injury, lysis of the myocyte and release of intracellular contents into the extracellular environment, including enzymes such as lactate dehydrogenase (LDH), aldolase, aspartate aminotransferase (AST), alanine aminotransferase (ALT) and creatine phosphokinase (CPK), as well as ions, such as potassium and phosphorus, myoglobin and uric acid, the latter due to increased catabolism of intracellular purines ${ }^{1,2}$. Its main complications are hyperkalemia, hypocalcemia, hyperuricemia, hepatic inflammation, cardiac arrhythmias, cardiac arrest and disseminated intravascular coagulation ${ }^{2-4}$. In later stages, the patient may develop compartment syndrome and acute renal injury, which is associated with high morbidity and mortality and is present in about $4 \%$ to $50 \%$ of cases $^{2,4}$. Regardless of the cause, the mortality rate can reach up to $8 \%{ }^{2}$.

The normal function of the myocyte is guaranteed by maintaining an ionic gradient (mainly sodium, potassium and calcium), which is established by the action of transmembrane transport proteins, such as sodium/potassium ATPase $\left(\mathrm{Na}^{+} / \mathrm{K}^{+}\right.$ATPase), whose enzymatic activities depend on the energy obtained from the degradation of adenosine triphosphate (ATP) $)^{3-5}$. In trauma (crush syndrome or crush injury) or depletion of the ATP stock (excessive consumption of alcohol or intense physical activity, for example), damage occurs to

1 - Federal University of Minas Gerais, Department of Surgery, Belo Horizonte, MG, Brazil. 2 - Federal University of Minas Gerais, Department of Preventive and Social Medicine, Belo Horizonte, MG, Brazil. 3 - Federal University of Minas Gerais, Faculty of Medicine, Belo Horizonte, MG, Brazil. 
transmembrane transport proteins and, consequently, to the cell membrane, resulting in ionic imbalance, with great intracellular influx of $\mathrm{Na}^{+}$and $\mathrm{Ca}^{++3,6}$. As a result, there is myocyte lysis, due to increased intracellular influx of water by osmosis, activation of $\mathrm{Ca}^{++}$-dependent proteases and phospholipases, persistent, $\mathrm{Ca}^{++}$-dependent myofibrillar contraction, and the inflammatory cascade resulting from pathological interactions from the established fibrosis and necrosis processes ${ }^{3-6}$. The progression of this muscle injury process results in rhabdomyolysis.

The findings of rhabdomyolysis are quantified mainly through levels of plasma CPK, an enzyme expressed by several cell types in different tissues, participating in the formation of phosphocreatine from creatine, depending on $\operatorname{ATP}^{3,7,8}$. The phosphocreatine thus formed acts as an intracellular phosphate reservoir, which can be used for the regeneration of adenosine diphosphate (ADP) in ATP, in order to maintain normal cellular functions ${ }^{7}$.

Trauma, whether penetrating or blunt, is associated with immediate elevation of plasma CPK values in laboratory analysis ${ }^{2,3}$. Acute myocardial infarction (AMI), muscular dystrophy, acute renal injury (ARI), autoimmune myositis, malignant neoplasms and other inflammatory processes of mainly muscular involvement are also related to elevated plasma CPK levels ${ }^{1,2,4}$. Thus, timely request and simple analysis of this biochemical marker are efficient ways to reduce the chance of progression of rhabdomyolytic disease, especially to ARI. In addition, the value of plasma CPK is directly proportional to the disorder or disintegration of striated muscle tissue, due to the concomitant leakage of intracellular muscle constituents into the circulation. Considering the normal concentration of $C P K<100 U / L$, concentrations five to ten times higher than the upper normal limit (such as 500-1000 U/L) are used to confirm rhabdomyolysis $1,2,4.8$.

Since plasma CPK analysis is a way to prevent progression to rhabdomyolysis and its complications and the level of circulating CPK is directly proportional to muscle injury (either direct damage or complications such as compartment syndrome and ARI) and consequently to the severity of the condition, this study aims to identify and analyze the factors associated with the greater variation of CPK during hospitalization in trauma patients submitted to the "Red Wave" protocol. Knowledge of these factors would allow reducing the chances of progression to rhabdomyolysis, early identification of complications associated with worsening of the rhabdomyolytic condition with increased CPK during hospitalization, and early intervention in the complications associated with greater CPK variation and, consequently, greater muscle damage.

\section{METHODS}

We conducted a prospective, longitudinal study, with a sample composed of 50 patients submitted to the "Red Wave" protocol between 2011 and 2015, with subsequent evolution to rhabdomyolysis after admission to the Risoleta Tolentino Neves Hospital, a tertiary university hospital which is reference for trauma, urgency and emergency care in North Belo Horizonte ${ }^{9}$. Victims of violent crimes are a considerable part of the care and population under analysis. The "Red Wave" can be described as a set of medical and administrative tactical actions whose objective is to perform thoracotomy and surgical procedures that promote the cessation of severe hemorrhagic states in an efficient and safe manner ${ }^{10}$.

Of the 50 patients in the sample, admission and final CPK values were present in the medical records of, respectively, 47 and 43 patients. We obtained the data from the RT (Collector $\AA$ ) database, and assessed the following variables: medical records, age, gender, RTS (Revised Trauma Score), ISS (Injurt Severity Score), TRISS (Trauma and Injury Severity Score), trauma mechanism and outcome, presence of digestive hemorrhage, acute renal injury, cardiac arrhythmia, compartment syndrome, compressive syndrome, hepatic, splenic, intestinal, thoracic, renal and vascular injuries, orthopedic fractures, traumatic brain injury, admission and final CPK levels, with the interval of days 
between them, and surgery (laparotomy, thoracotomy, orthopedic or other).

The ISS is an anatomical scoring system, based on the assignment of values from 1 to 6 (Abbreviated Injury Scale, where 1 means minor, 2 moderate, 3 serious, 4, severe/life threatening, 5 critical/uncertain survival and 6 , non-survivor) for each lesion, considering each of the six regions of the body: head and neck, face, chest, abdomen, extremities (including pelvis) and outer surface. In the case of multiple lesions, only the highest values for each region are used, and the three largest values, in different body segments, are folded and summed to produce the index. The values range from 0 to 75, so that if any lesion equals 6 , in any segment, the ISS is 75 automatically ${ }^{11}$. RTS is a physiological scoring system, with great reliability and accuracy to predict death, being calculated from the first measurement of the Glasgow Coma Scale (ECG), systolic blood pressure $(\mathrm{SBP})$ and respiratory rate $(\mathrm{RR})$, ranging from 0 to $7.8408^{12}$. We considered ISS levels below 25 as low or moderate severity trauma; 25 to 34 , severe trauma; 35 or more, very severe trauma ${ }^{13}$. We considered that the probability of survival was satisfactory when RTS was equal to or higher than 6 , that is, probability greater than $90 \%{ }^{1}$.

We created six specific variables, which represent the distribution of admission and final CPK values in three distinct categories each: less than $<500 U / L ; \geq 500 U / L-<1000 U / L ; \geq 1000 U / L^{8}$. In addition, we created another specific variable that represents the absolute value of the difference between the final and admission CPK values.

Once the variables were organized, we performed the statistical analysis with the SPSS Release 23.0.0.0 software for Windows. We expressed continuous variables as mean and standard deviation, and analyzed them using the Student's t-test; we analyzed categorical variables with the Pearson's chi- square or Fisher's test (if the expected number of cases in one category was less than 5), this being a univariate analysis. We determined the predictors independently associated with CPK difference by linear regression analysis. Values that had significance less than $20 \%$ $(p<0.20)$ in the univariate analysis were included in a linear model and the final model was obtained by sequential deletion of variables. For this model, we categorized some continuous variables. The level considered for significant results was $5 \%(p<0.05)$. In order to evaluate the obtained multivariate model, we performed the imtest test implemented in the software that, in addition to assessing the heteroskedasticity of the final model, also tests for kurtosis and asymmetry of the predicted data.

The study was approved by the Ethics in Research Committee of the UFMG and the Risoleta Tolentino Neves Hospital, and submitted to the Plataforma Brasil (CAAE: 44349515.5.0000.5149).

\section{RESULTS}

The main descriptive results associated with admission CPK categories are shown in table 1. The 47 patients had a mean age of 39.1 years $( \pm 16.8)$ and were mostly men (83.0\%; $n=39)$. The most common trauma mechanism was the blunt $(68.1 \%, n=32)$. The mean RTS was compatible with survival over $90 \%(6.9 ; \pm 1.74)$ and the ISS with low and moderate severity trauma (22.9; \pm 12.4 ). Forty-five patients (95.7\%) underwent some surgical procedure, with a predominance of laparotomy (46.8\%; $n=22$ ). As for lesions and complications, the most common was orthopedic fracture $(n=33,70.2 \%)$, followed by thoracic injury $(n=24,51.1 \%)$, digestive hemorrhage $(n=17,36.2 \%)$, acute renal injury $(n=16,34 \%)$, liver injury $(n=13,27.7 \%)$ and intestinal lesion $(n=13,27.7 \%)$. 
Table 1. Results according to CPK range on admission.

\begin{tabular}{|c|c|c|c|c|c|}
\hline & $\begin{array}{l}\text { Total } \\
(n=47)\end{array}$ & $\begin{array}{l}\text { Admission CPK } \\
<500(n=4)\end{array}$ & $\begin{array}{c}\text { Admission CPK } \\
\geq 500 \text { and }<1000(n=4)\end{array}$ & $\begin{array}{l}\text { Admission CPK } \\
\geq 1000(n=39)\end{array}$ & $p$ \\
\hline Age in years: mean (SD) & $39.1(16.78)$ & $59.8(29.06)$ & $36.5(14.62)$ & $37.3(14.43)$ & \\
\hline \multicolumn{6}{|l|}{ Gender: n (\%) } \\
\hline Male & $39(83)$ & $2(89.4)$ & $3(75)$ & $34(87.2)$ & \multirow{2}{*}{0.154} \\
\hline Female & $8(17)$ & $2(10.6)$ & $1(25)$ & $5(12.8)$ & \\
\hline \multicolumn{6}{|l|}{ Trauma mechanism: n (\%) } \\
\hline Blunt & $32(68.1)$ & $2(50)$ & $2(50)$ & $28(71.8)$ & \multirow{2}{*}{0.484} \\
\hline Penetrating & $15(31.9)$ & $2(50)$ & $2(50)$ & $11(28.2)$ & \\
\hline \multicolumn{6}{|l|}{ Trauma outcome: n (\%) } \\
\hline Died & $10(21.3)$ & $3(75)$ & $2(50)$ & $5(12.8)$ & \multirow{2}{*}{0.005} \\
\hline Survived & $37(78.7)$ & $1(25)$ & $2(50)$ & $34(87.2)$ & \\
\hline RTS: mean (SD) & $6.91(1.74)$ & $7.22(0.73)$ & $5.27(3.64)$ & $7.06(1.47)$ & \\
\hline ISS: mean (SD) & $22.94(12.42)$ & $15.25(4.57)$ & $20.75(5.74)$ & $23.95(13.22)$ & \\
\hline TRISS: mean (SD) & $0.86(0.25)$ & $0.927(0.061)$ & $0.698(0.404)$ & $0.874(0.238)$ & \\
\hline ICU stay: n (\%) & $42(89.4)$ & $4(100)$ & $4(100)$ & $34(89.4)$ & 0.563 \\
\hline Gastrointestinal bleeding: $\mathrm{n}(\%)$ & $17(36.2)$ & $3(75)$ & $2(50)$ & $12(30.8)$ & 0.179 \\
\hline Acute renal injury: $\mathrm{n}(\%)$ & $16(34)$ & $3(75)$ & $1(25)$ & $12(30.8)$ & 0.190 \\
\hline Cardiac arrhythmia: n (\%) & $0(0)$ & $0(0)$ & $0(0)$ & $0(0)$ & N/A \\
\hline Compartmental Sd: n (\%) & $4(8.5)$ & $1(25)$ & $0(0)$ & $3(7.7)$ & 0.406 \\
\hline Compressive Sd: n (\%) & $0(0)$ & $0(0)$ & $0(0)$ & $0(0)$ & N/A \\
\hline Intestinal injury: n (\%) & $13(27.7)$ & $2(50)$ & $1(25)$ & $10(25.6)$ & 0.579 \\
\hline Liver injury: n (\%) & $13(27.7)$ & $1(25)$ & $1(25)$ & $11(28.2)$ & 0.983 \\
\hline Splenic injury: n (\%) & $5(10.6)$ & $0(0)$ & $0(0)$ & $5(12.8)$ & 0.563 \\
\hline Kidney injury: n (\%) & $3(6.4)$ & $1(25)$ & $1(25)$ & $1(2.6)$ & 0.061 \\
\hline Vascular injury: n (\%) & $3(6.4)$ & $0(0)$ & $1(25)$ & $2(5.1)$ & 0.260 \\
\hline Orthopedic fracture: n (\%) & $33(70.2)$ & $3(75)$ & $2(50)$ & $28(71.8)$ & 0.647 \\
\hline TBI: n (\%) & $3(6.4)$ & $0(0)$ & $0(0)$ & $3(7.7)$ & 0.720 \\
\hline Thoracic lesion: n (\%) & $24(51.1)$ & $0(0)$ & $1(25)$ & $23(59)$ & 0.044 \\
\hline Underwent surgery: n (\%) & $45(95.7)$ & $4(100)$ & $4(100)$ & $37(94.9)$ & 0.807 \\
\hline Thoracotomy: n (\%) & $12(25.5)$ & $0(0)$ & $0(0)$ & $12(30.8)$ & 0.192 \\
\hline Laparotomy: n (\%) & $22(46.8)$ & $2(50)$ & $3(75)$ & $17(43.6)$ & 0.483 \\
\hline Orthopedic surgery: n (\%) & $3(6.4)$ & $0(0)$ & $1(25)$ & $2(5.1)$ & 0.260 \\
\hline Other surgery: n (\%) & $5(10.6)$ & $1(25)$ & $1(25)$ & $3(7.7)$ & 0.351 \\
\hline
\end{tabular}

$S D=$ Standard deviation; $S d=$ syndrome; ICU=Intensive Care Unit; TBI= traumatic brain injury; N/a= not applicable.

Regarding the CPK admission levels, the majority of patients presented values greater than or equal to 500 $(n=43 ; 91.49 \%)$, with the predominance of patients with CPK greater than or equal to $1000(n=39,82.98 \%)$. Of these, the mean age was 37.3 years $( \pm 14.43)$ and were mostly men $(87.2 \% ; n=34)$. The most common trauma mechanism was the blunt $(71.8 \% ; n=28)$. The mean RTS was compatible with survival above $90 \%(7.06 ; \pm 1.47)$ and the ISS, with low and moderate severity trauma $(23.95 ; \pm 13.22)$. The mean ICU time lengths were longer than 30 days. Thirty-seven patients (94.9\%) underwent surgery, with a predominance of laparotomy (43.6\%, $n=17)$, followed by thoracotomy $(30.8 \%, n=12)$. As for lesions and complications, the most common was the 
orthopedic fracture $(n=28,71.8 \%)$, followed by thoracic injury $(n=23,59 \%)$, digestive hemorrhage $(n=12$, $30.8 \%)$, acute renal injury $(n=12,30.8 \%)$, liver injury $(n=11,28.2 \%)$ and intestinal lesion $(n=10,25.6 \%)$.

There were significant differences between means and proportions for the following variables regarding the stratification by $\mathrm{CPK}$ at admission: trauma outcome $(p=0.005)$, with predominance of the blunt between patients with higher levels of CPK, and chest injury $(p=0.044)$, more frequent in patients with higher levels of CPK.

The results of the final CPK categories are shown in table 2 . The 43 patients had a mean age of
40.19 years $( \pm 16.6)$, with a predominance of men (81.4\%; $n=35)$. The most common trauma mechanism was the blunt $(67.4 \%, n=29)$. The mean RTS was compatible with survival greater than $90 \%(n=7 ; \pm 1.69)$ and the ISS, with low and moderate severity trauma (22.58; \pm 12.88$)$. The mean length of ICU stay was 35 days. Forty-two patients (97.7\%) underwent surgery, with a predominance of laparotomy $(46.5 \% ; n=20)$. As for lesions and complications, the most common was orthopedic fracture $(n=29,67.4 \%)$, followed by thoracic injury $(n=21,48.8 \%)$, digestive hemorrhage $(n=15$, $34.9 \%)$, acute renal injury $(n=15,34.9 \%)$, intestinal lesion ( $n=12,27.9 \%)$, and hepatic injury ( $n=11,25.6 \%)$.

Table 2. Results according to CPK final levels.

\begin{tabular}{|c|c|c|c|c|c|}
\hline & $\begin{array}{l}\text { Total } \\
(n=43)\end{array}$ & $\begin{array}{c}\text { Final CPK } \\
<500(n=26)\end{array}$ & $\begin{array}{c}\text { Final CPK } \\
\geq 500 \text { and }<1000(n=9)\end{array}$ & $\begin{array}{c}\text { Final CPK } \\
\geq 1000(n=8)\end{array}$ & $\mathrm{p}$ \\
\hline Age in years: mean (SD) & $40.2(16.6)$ & $44.6(17.6)$ & $31(10.9)$ & $36.1(14.6)$ & \\
\hline Male: n (\%) & $35(81.4)$ & $21(80.8)$ & $8(88.9)$ & $6(75.0)$ & 0.757 \\
\hline Blunt mechanism: n (\%) & $29(67.4)$ & $17(65.4)$ & $6(66.7)$ & $6(75.0)$ & 0.878 \\
\hline Death as outcome: n (\%) & $9(20.9)$ & $4(15.4)$ & $1(11.1)$ & $4(50.0)$ & 0.078 \\
\hline RTS: mean (SD) & $7(1.69)$ & $7.24(1.12)$ & $6.87(1.84)$ & $6.49(2.7)$ & \\
\hline ISS: mean (SD) & $22.58(12.88)$ & $21.15(10.77)$ & $23(10.68)$ & $26.75(20.6)$ & \\
\hline TRISS: mean (SD) & $0.87(0.25)$ & $0.92(0.16)$ & $0.87(0.26)$ & $0.73(0.39)$ & \\
\hline ICU stay: n (\%) & $38(88.4)$ & $24(92.3)$ & $6(66.7)$ & $8(100)$ & 0.062 \\
\hline Gastrointestinal bleeding: $\mathrm{n}(\%)$ & $15(34.9)$ & $9(34.6)$ & $2(22.2)$ & $4(50)$ & 0.487 \\
\hline Acute kidney injury: n (\%) & $15(34.9)$ & $10(38.5)$ & $2(22.2)$ & $3(37.5)$ & 0.668 \\
\hline Cardiac arrhythmia: n (\%) & $0(0)$ & $0(0)$ & $0(0)$ & $0(0)$ & N/A \\
\hline Compartmental Sd: n (\%) & $3(7)$ & $2(7.7)$ & $0(0)$ & $1(12.5)$ & 0.585 \\
\hline Compressive Sd: n (\%) & $0(0)$ & $0(0)$ & $0(0)$ & $0(0)$ & N/A \\
\hline Intestinal Injury: n (\%) & $12(27.9)$ & $7(26.9)$ & $3(33.3)$ & $2(25)$ & 0.915 \\
\hline Liver injury: n (\%) & $11(25.6)$ & $7(26.9)$ & $3(33.3)$ & $1(12.5)$ & 0.598 \\
\hline Splenic Injury: n (\%) & $4(9.3)$ & $2(7.7)$ & $1(11.1)$ & $1(12.5)$ & 0.9 \\
\hline Kidney injury: n (\%) & $3(7)$ & $2(7.7)$ & $0(0)$ & $1(12.5)$ & 0.585 \\
\hline Vascular injury: n (\%) & $3(7)$ & $2(7.7)$ & $0(0)$ & $1(12.5)$ & 0.585 \\
\hline Orthopedic fracture: n (\%) & $29(67.4)$ & $17(65.4)$ & $7(77.8)$ & $5(62.5)$ & 0.749 \\
\hline TBI: n (\%) & $2(4.7)$ & $1(3.8)$ & $1(11.1)$ & $0(0)$ & 0.529 \\
\hline Thoracic injury: n (\%) & $21(48.8)$ & $14(53.8)$ & $4(44.4)$ & $3(37.5)$ & 0.690 \\
\hline Underwent surgery: n (\%) & $42(97.7)$ & $26(100)$ & $8(88.9)$ & $8(0)$ & 0.145 \\
\hline Thoracotomy: n (\%) & $11(25.6)$ & $5(19.2)$ & $3(33.3)$ & $3(37.5)$ & 0.489 \\
\hline Laparotomy: n (\%) & $20(46.5)$ & $10(38.5)$ & $4(44.4)$ & $6(75)$ & 0.192 \\
\hline Orthopedic surgery: n (\%) & $2(4.7)$ & $1(3.8)$ & $1(11.1)$ & $0(0)$ & 0.529 \\
\hline Other surgery: n (\%) & $5(11.6)$ & $4(15.4)$ & $0(0)$ & $1(12.5)$ & 0.461 \\
\hline
\end{tabular}

$S D=$ Standard deviation; $S d=$ syndrome; $I C U=$ Intensive Care Unit; $T B /=$ traumatic brain injury; N/a= not applicable. 
Regarding the final CPK ranges, the majority of patients had values lower than 500 ( $n=26 ; 60.47 \%$ ). Of these, the mean age was 44.62 years $( \pm 17.61)$ and they were mostly men $(80.8 \% ; n=21)$. The most common trauma mechanism was the blunt $(65.4 \%, n=17)$. The mean RTS was compatible with survival above $90 \%$ $(7.24 ; \pm 1.12)$ and the ISS, with low and moderate severity trauma $(21,15 ; \pm 10,77)$. The mean time of ICU stay was 21 days. Twenty-six (100\%) underwent surgery, with a predominance of laparotomy $(38.5 \% ; n=10)$. The most common lesions and complications were orthopedic fractures $(n=17,65.4 \%)$, followed by thoracic injury $(n=14,53.8 \%)$, acute renal injury $(n=10,38.5 \% \%)$ and digestive hemorrhage $(n=9 ; 34.6 \%)$.

There were no significant differences between means and proportions for the variables regarding stratification by the final CPK value: trauma outcome $(p=0.078)$, and time, in days, of ICU admission $(p=0.062)$.

Table 3 shows the mean CPK changes during the hospitalization period, according to the variables of the 43 patients with final CPK value filled in the sample. The highest mean variation observed was compartment syndrome $(13658.67, \pm 8024.04)$, followed by intestinal lesion (7143.42, \pm 3125.68$)$, digestive hemorrhage $(6494.8, \pm 2502.51)$, TBI $(6150.5, \pm 2018.5)$ and laparotomy $(5331.55, \pm 1921.48)$. The lowest mean variation was related to orthopedic surgery (1469, $\pm 1010)$, followed by renal injury $(1815.67, \pm 1586.47)$, vascular lesion $(2232.67, \pm 912.95)$ and female gender $(2490.75, \pm 783.98)$.

Table 3. Results of patients stratification according to the CPK variation during hospitalization.

\begin{tabular}{lcc}
\hline & $\begin{array}{c}\text { Variation of CPK } \\
\text { (Final CPK - Admission CPK) } \\
\text { Mean (SD) }=4261(6105)\end{array}$ & $p$ \\
\hline Gender & & \\
$\quad$ Male & $4666(1123)$ & 0.121 \\
$\quad$ Female & $2491(784)$ & 0.168 \\
ICU stay & $4478(1046)$ & 0.197 \\
Gastrointestinal bleeding & $6495(2503)$ & 0.192 \\
Acute renal injury & $2897(815)$ & 0.004 \\
Compartmental Sd: mean (SD) & $13659(8024)$ & 0.053 \\
Intestinal injury: mean (SD) & $7143(3126)$ & 0.141 \\
Vascular injury: mean (SD) & $2233(913)$ & 0.145 \\
Orthopedic fracture: mean (SD) & $3313(537)$ & 0.112 \\
Orthopedic surgery: mean (SD) & $1469(1010)$ & 0.187 \\
Other surgery: mean (SD) & $2557(938)$ & \\
\hline
\end{tabular}

$S D=$ Standard deviation; $S d=$ syndrome; ICU=Intensive Care Unit; $T B I=$ traumatic brain injury; N/a= not applicable.

The values with significance lower than $20 \%$ $(p<0.20)$ included in the final linear regression model were gender $(p=0.121)$, ICU stay $(p=0.168)$, digestive hemorrhage $(p=0.197)$, acute renal injury $(p=0.112)$, compartment syndrome $(p=0.004)$, intestinal lesion $(p=0.053)$, vascular injury $(p=0.141)$, orthopedic fracture $(p=0.145)$, orthopedic surgery $(p=0.112)$, and other surgeries $(p=0.187)$.

Table 4 indicates the factors that were independently and positively associated with CPK variation: positively, hospitalization time greater than one week and compartment syndrome, and negatively, acute renal injury. There was no evidence of heteroscedasticity $(p=0.784)$, asymmetry $(p=0.403)$, or kurtosis $(p=0.260)$. 
Table 4. Factors independently associated with the CPK difference.

\begin{tabular}{lccc}
\hline \multicolumn{1}{c}{ Variable } & Coefficient & $95 \%$ Cl (robust) & p-value \\
\hline Length of stay (reference: up to 7 days) & 4221 & $1224 ; 7218$ & 0.007 \\
Acute renal injury (reference: absent) & -3296 & $-6307 ;-285$ & 0.033 \\
Compartment syndrome (reference: absent) & 11474 & $1179 ; 14064$ & 0.033 \\
Linear regression equation intercept & 1567 & $-161.7 ; 3296$ & 0.074 \\
\hline
\end{tabular}

\section{DISCUSSION}

In patients studied with ARI, CPK at admission was lower than those without ARI, with a trend towards statistical significance $(p=0.096)$, a difference not observed in the stratification of patients with compartment syndrome. Statistically, this is the reason why the presence of ARI is associated with negative differences in CPK in the presence of other factors, such as hospitalization longer than one week and compartment syndrome. In practice, this result may represent that patients with rhabdomyolysis and lower admission severity, represented by lower CPK, are more likely to progress to ARI, but it should also be considered that CPK has peaks within 24 to 72 hours, and then declines gradually in seven to ten days, which may influence the results found depending on the length of time the patient is hospitalized ${ }^{1}$. Thus, there is a need for more studies on this relationship.

In rhabdomyolysis, clinical findings are quantified from the laboratory analysis of CPK levels, which are typically elevated in such patients, thus constituting an important biomarker of the disease ${ }^{2,14}$. Thus, the literature establishes the CPK threshold greater than 500U/L to define significant rhabdomyolysis; other studies define CPK of $1000 \mathrm{U} / \mathrm{L}$ as the lower limit for diagnosis ${ }^{14}$. Thus, the present study, based on previous studies, suggests the value of $1000 \mathrm{U} / \mathrm{L}$ as the lower limit for CPK analysis, since $83 \%$ of the admission values of the patients admitted to the "Red Wave" with clinical diagnosis of rhabdomyolysis were above this threshold 8,15 .

Rhabdomyolysis is basically a consequence of muscle injury, mainly associated with compartment syndrome, trauma (crush injury or reperfusion injury), and the most severe complication present in $13 \%$ to $50 \%$ of cases is ARI. Myoglobin deposit leads to renal vasoconstriction, intratubular deposits, and direct damage to the renal tubules ${ }^{1,16}$. At admission, the patients in the present study had mainly orthopedic fracture $(71.8 \%)$ and thoracic injury (59\%), typically associated with trauma and, consequently, with muscle injury. ARI was present in about $31 \%$ of the patients, within the historical range of the literature.

Rapid diagnosis and early intervention are essential for patient prognosis. In most cases, renal function, a major concern in this syndrome, recovers and the survival rate is around $78 \%{ }^{17}$. Of the patients with CPK value assessed at the end of hospitalization, approximately $61 \%$ presented normalization of its levels $(<500 \mathrm{U} / \mathrm{L})$. In addition, the survival rate was around $79 \%$ for all patients. Patients with CPK $>1000 \mathrm{U} / \mathrm{L}$ on admission had the highest survival rates in the study, probably because they demanded more attention from the medical team, with surgical procedures. The same was not observed for patients in the same category $(\mathrm{CPK}>1000 \mathrm{U} / \mathrm{L})$ at the end of hospitalization, with survival of $50 \%$, due to the worse prognosis and irreversibility of the condition.

The early diagnosis of rhabdomyolysis is mainly related to the recognition of a clinical condition compatible with the syndrome, before the laboratory evaluation of CPK levels, which, despite being a simple and cost-effective biochemical marker, may require extra essential time to the critical management in the emergency room. Concurrently, an effective treatment represents the effective management of the main lesions, so that the relation of an injury to the evolution of the patient's clinical condition can be quantified from the variation of the CPK levels ${ }^{2,17}$.

In this context, trauma alone is a common cause of rhabdomyolysis, either by the compression and associated muscle injury, or by concomitant lesions, requiring proper management. The present study points to digestive hemorrhage, acute renal injury and 
compartment syndrome as variables that are statistically associated with a greater variation in CPK levels during hospitalization, independent of other factors, thus requiring greater attention from emergency teams ${ }^{16}$. Digestive hemorrhage, although severe and present in the descriptive results according to CPK variation during hospitalization, did not enter into the final model of the factors independently associated with CPK difference, probably because the other factors had a greater impact on CPK.

The present study indicated a higher ratio of rhabdomyolysis with CPK values above 500U/L, and especially $>1000 \mathrm{U} / \mathrm{L}$, at admission, in association with orthopedic fracture, followed by thoracic injury, digestive hemorrhage, acute renal injury, liver injury and intestinal lesion, and in patients submitted to laparotomy, mainly, and thoracotomy. From a practical point of view, the need for early request of plasma CPK in trauma victims is reinforced, with a value of $1000 \mathrm{U} / \mathrm{L}$ as the lower limit for analysis. In addition, the clinical picture of the patient and the complications presented should be evaluated in order to intervene early in conditions related to aggravation of muscle injury and, consequently, rhabdomyolysis, such as orthopedic fracture, digestive hemorrhage and acute renal injury. However, there is a need for further studies in the area, in order to obtain a larger sample of comparative data.

\title{
R E S U M O
}

\begin{abstract}
Objetivo: identificar e analisar fatores associados à variação dos níveis plasmáticos de creatina fosfoquinase (CPK) em vítimas de trauma com evolução à rabdomiólise. Métodos: estudo longitudinal prospectivo, com 50 pacientes que seguiram para o protocolo "Onda Vermelha", com evolução à rabdomiólise, após admissão hospitalar. Foram estudadas as variáveis: idade, sexo, escores, mecanismo e desfecho de trauma, CPK na admissão e final, intervalos de dias entre as avaliações laboratoriais, realização de cirurgia e complicações. Os valores da CPK foram estratificados em $<500 \mathrm{U} / \mathrm{L} ; \geq 500$ - $<1000 \mathrm{U} / \mathrm{L} ; \geq 1000 \mathrm{U} / \mathrm{L}$, com cálculo da diferença entre os valores inicial e final. Resultados: à admissão, $83 \%$ dos pacientes ( $n=39$ ) apresentavam $C P K \geq 1000 U / L$, com predomínio de trauma contuso e lesão torácica $(p<0,05)$, além de fratura ortopédica, lesão renal aguda e hemorragia digestiva, sendo que a CPK era menor naqueles sem lesão renal aguda, com tendência à significância estatística. Não houve diferenças na estratificação por CPK final. Fatores que se revelaram independentemente associados à maior variação da CPK foram, positivamente, o tempo de internação superior a uma semana e síndrome compartimental, e negativamente, lesão renal aguda. Conclusão: como achado, nível de CPK de 1000U/L permanece como limite inferior, com importância à intervenção precoce em condições de agravamento do quadro, como hemorragia digestiva, lesão renal aguda e síndrome compartimental, que implicaram maiores diferenças absolutas entre CPK inicial e final, além do trauma contuso, lesão torácica e fratura ortopédica.
\end{abstract}

Descritores: Rabdomiólise. Creatina Quinase. Serviços Médicos de Emergência.

\section{REFERENCES}

1. Petejova N, Martinek A. Acute kidney injury due to rhabdomyolysis and renal replacement therapy: a critical review. Crit Care. 2014;18(3):224.

2. Bagley $\mathbf{W H}$, Yang $\mathrm{H}$, Shah $\mathrm{KH}$. Rhabdomyolysis. Intern Emerg Med. 2007;2(3):210-8.

3. Khan FY. Rhabdomyolysis: a review of the literature. Neth J Med. 2009;67(9):272-83.

4. Rosa NG, Silva G, Teixeira A, Rodrigues F, Araújo JA. Rabdomiólise. Acta Méd Port. 2005;18(4):271-82.

5. Vanholder R, Sever MS, Erek E, Lameire $N$.
Rhabdomyolysis. J Am Soc Nephrol. 2000;11(8):155361.

6. Malinoski DJ, Slater MS, Mullins RJ. Crush injury and rhabdomyolysis. Crit Care Clin. 2004;20(1):171-92.

7. Baynes JW, Dominiczak MH. Bioquímica médica. 3. ed. Rio de Janeiro: Elsevier, 2011.

8. Torres PA, Helmstetter JA, Kaye AM, Kaye AD. Rhabdomyolysis: pathogenesis, diagnosis, and treatment. Ochsner J. 2015;15(1):58-69.

9. Miranda B. Hospital das Clínicas e Risoleta Neves reduzem leitos. O Tempo. Belo Horizonte. [Internet]. 2015 Jan 21. [cited 2017 fev 17]. Disponível em: 
http://www.otempo.com.br/cidades/hospitaldas-cl\% C3\% ADnicas-e-risoleta-neves-reduzemleitos-1.977233

10. Palmer C. Major trauma and the injury severity score-where should we set the bar? Annu Proc Assoc Adv Automot Med. 2007;51:13-29.

11. Champion HR, Sacco WJ, Copes WS, Gann DS, Gennarelli TA, Flanagan ME. A revision of the Trauma Score. J Trauma. 1989;29(5):623-9.

12. Rezende $R$, Avanzi O. Importância do Índice Anatômico de Gravidade do Trauma no manejo das fraturas toracolombares do tipo explosão. Rev Col Bras Cir. 2009;36(1):9-13.

13. Alvarez BD, Razente DM, Lacerda DA, Lother NS, Von Bahten, Stahlschmidt CM. Analysis of the Revised Trauma Score (RTS) in 200 victims of different trauma mechanisms. Rev Col Bras Cir. 2016;43(5): 334-40.

14. Lima RS, da Silva Junior $G B$, Liborio $A B$, Daher EF. Acute kidney injury due to rhabdomyolysis. Saudi J Kidney Dis Transpl. 2008;19(5):721-9.

15. Brown CV, Rhee P, Chan L, Evans K, Demetriades $D$, Velmahos GC. Preventing renal failure in patients with rhabdomyolysis: do bicarbonate and mannitol make a difference? J Trauma. 2004;56(6):1191-6.

16. Nayak $S$, Jindal A. Myoglobinuria and acute kidney injury. J Integr Nephrol Androl. 2015;2(2):50-4.

17. Keltz E, Khan FY, Mann G. Rhabdomyolysis. The role of diagnostic and prognostic factors. Muscles Ligaments Tendons J. 2014;3(4):303-12.

Received in: 14/11/2017

Accepted for publication: 22/01/2018

Conflict of interest: none.

Source of funding: CNPq Research Productivity Grant of the corresponding author. Bolsa PIBIC / CNPq of the second author.

\section{Mailing address:}

Carla Jorge Machado

E-mail: carlajmachado@gmail.com / carlajm@ufmg.br

\section{(cc) BY}

